\title{
An epizootic of Caligus chiastos on farmed southern bluefin tuna Thunnus maccoyii off South Australia
}

\author{
Craig J. Hayward ${ }^{1,2, *}$, Hamish M. Aiken ${ }^{1}$, Barbara F. Nowak ${ }^{1}$ \\ ${ }^{1}$ School of Aquaculture and Aquafin Cooperative Research Centre, University of Tasmania, Locked Bag 1-370, Launceston, \\ Tasmania 7250, Australia \\ ${ }^{2}$ Present address: South Australian Research and Development Institute, Lincoln Marine Science Centre, PO Box 1511, \\ Port Lincoln, South Australia 5606, Australia
}

\begin{abstract}
In some years, large numbers of Caligus chiastos have been observed on the external surfaces of southern bluefin tuna, particularly on the head and eyes, in some sea cages in Spencer Gulf, Australia. As no epidemiological data were available, we monitored sea lice on tuna $(\mathrm{N}=130)$ in 4 research cages sampled at 6 wk intervals during the 2005 farming season. No lice were observed on a sample of 10 wild-caught tuna when the cohort was transferred to cages in early April. By late May more than half the sampled tuna (22 of 40) were infected, with up to 42 parasites; we also recorded one unidentified Caligus sp. at this time. In early July the number of tuna infected with lice declined to $10 \%$; in the final sample in late August none were detected. Prevalence in May was significantly higher than on other dates ( $\mathrm{p} \leq 0.001)$, whereas mean abundances did not differ significantly $(\mathrm{p}>0.05)$. The decline in prevalence corresponded with a seasonal fall in temperature, from ca. $17^{\circ} \mathrm{C}$ in May to $14^{\circ} \mathrm{C}$ in August. Counts of lice at the peak of infection were associated with the severity of eye damage (Spearman's rank correlation coefficient, $r_{\mathrm{S}, 38 \mathrm{df}}=0.654, \mathrm{p}<0.001$ ); this may be because lice graze on the cornea or because tuna injure their eyes when flashing (rubbing against objects). Counts at this time were also strongly and inversely correlated with the condition index $\left(\mathrm{r}_{\mathrm{S}, 38 \mathrm{df}}=-0.707, \mathrm{p}<0.001\right)$. It appears that tuna become infested with adult sea lice via wild teleosts and elasmobranchs attracted to sea cages.
\end{abstract}

KEY WORDS: Sea lice $\cdot$ Caligids $\cdot$ Copepoda $\cdot$ Parasite $\cdot$ Southern bluefin tuna $\cdot$ Thunnus maccoyii Epidemiology Resale or republication not permitted without written consent of the publisher

\section{INTRODUCTION}

Sea lice are parasitic copepods belonging to the Family Caligidae that attach to the external surfaces of fish. They are also amongst the most notorious pests affecting farmed marine fishes (Lester \& Hayward 2006). The best-known representatives of this group are those infesting farmed salmonids; in particular, infections of Lepeophtheirus salmonis and Caligus elongatus seriously hamper production of Atlantic salmon Salmo salar in the Northern Hemisphere (Pike \& Wadsworth 1999). C. elongatus has very low specificity for fish hosts and, based upon the taxonomic review of Parker (1969), had been thought to be widespread around the world. However, a recent examination of sequences of mitochondrial cytochrome c oxi- dase indicated that material identifiable as C. elongatus off Norway belongs to 2 distinct clades (Øines \& Heuch 2005). In addition, some of the records of $C$. elongatus and $C$. rapax on wild fishes off southern Australia and New Zealand (see Parker 1969, Rough 2000, Munday et al. 2003) may in fact belong to a recently erected species, C. chiastos Lin et Ho, 2003. This species is known from a range of wild teleosts in Taiwan (Ho \& Lin 2004), including Caranx sexfasciatus, Otolithes ruber, Pelates quadrilineatus and Plectorhinchus cinctus, and the species is considered to be relatively rare.

Caligus chiastos has also been found on the external surfaces of a highly valuable aquaculture species farmed off Port Lincoln in South Australia: southern 
bluefin tuna Thunnus maccoyii (see C. J. Hayward et al. unpubl.). However, anecdotal evidence suggests that there is a large spatial and temporal variability in these infections. C. chiastos has also been identified (at the time as $C$. cf elongatus) in the same local area as farmed mulloway Argyrosomus japonicus and yellowtail kingfish Seriola lalandi (see Hayward et al. 2007b). Rough (2000) detected this species (at the time identified as $C$. elongatus) on farmed T. maccoyii in all years between 1995 and 2000, but not in the first year of the study, 1994. No quantitative data are currently available, but sea lice have been reported to be most abundant on the heads and eyes of the tuna; infections were also reported to be associated with eye damage (keratitis, panopthalmitis and cataracts) and blindness, leading to significant production losses (Rough 2000, Munday et al. 2003). In Nowak's (2004) assessment of the health risks to farmed T. maccoyii, the overall risk of C. chiastos (listed as C. elongatus) to tuna farming was classified as very low, but monitoring of this species was recommended, especially if tuna were farmed for longer than one season. There are currently no epidemiological data available for C. chiastos on any hosts. Anecdotal reports that sea lice are associated with eye damage and blindness in southern bluefin tuna require confirmation with quantitative data. We aimed to collect prevalence and intensity data for $C$. chiastos among tuna at regular intervals during a season of farming and determine whether sea lice counts on individual tuna are indeed correlated with the severity of gross pathology of the eye.

\section{MATERIALS AND METHODS}

Approximately 3 yr old, wild southern bluefin tuna Thunnus maccoyii (Castelnau, 1872) were purseseined in the Great Australian Bight $\left(33^{\circ} 27^{\prime} \mathrm{S}, 132^{\circ} 04^{\prime} \mathrm{E}\right)$ on February 19 , 2005, transferred into a towing pontoon and towed to Port Lincoln. This cohort of tuna was then transferred into 4 sea cages, each of $32 \mathrm{~m}$ diameter, by catching each individual using a baited, barbless hook and line, measuring the length and weight and inserting a conventional dart tag before release into the destination sea cage. Tuna were transferred on the following dates: April 5 (Cage 1), 6 (Cage 2), 8 (Cage 3) and 10 (Cage 4). Each cage was fed on a different diet
Table 2. Thunnus maccoyii. Sample data for southern bluefin tuna over a 4.5 mo farming period in 2005, examined for sea lice. The temperature $(T)$ given for July 11 was that recorded on July 22, the first date after the telemetry system was functioning. na: not available

\begin{tabular}{|lccccrr|}
\hline Date in 2005 & $\begin{array}{c}T \\
\left({ }^{\circ} \mathrm{C}\right)\end{array}$ & Cages & $\mathrm{n}$ & $\begin{array}{c}\text { Mean whole } \\
\text { weight } \\
(\mathrm{kg} \pm \mathrm{SD})\end{array}$ & $\begin{array}{c}\text { Mean length } \\
(\mathrm{cm} \pm \mathrm{SD})\end{array}$ & $\begin{array}{c}\text { Mean } \\
\text { condition } \\
\text { index } \pm \mathrm{SD}\end{array}$ \\
\hline April 5 & 19.6 & na & 10 & $13.4 \pm 4.0$ & $90.4 \pm 7.3$ & $17.7 \pm 1.2$ \\
May 31 & 16.7 & $1-4$ & 40 & $23.0 \pm 5.3$ & $102.3 \pm 8.7$ & $21.3 \pm 2.5$ \\
July 11 & 14.4 & $1-4$ & 40 & $20.6 \pm 5.0$ & $93.0 \pm 7.6$ & $25.1 \pm 2.5$ \\
August 22 & 13.8 & $1-4$ & 40 & $25.4 \pm 6.4$ & $99.9 \pm 9.0$ & $25.0 \pm 1.5$ \\
Total & & & 130 & & & \\
\hline
\end{tabular}

as part of a collaborative research project and maintained at similar stocking densities (see Table 1). Before transfer into sea cages, 10 tuna were initially examined on April 5, 2005. Further samples of tuna were examined for skin parasites at ca. $6 \mathrm{wk}$ intervals, on May 31, July 11 and August 22, over a total period of just over $4.5 \mathrm{mo}$; total monthly sample sizes and collection dates are presented in Table 2. Sample sizes were limited to 10 per sea cage because of the exceptionally high value of individual tuna (on avg. ca. US\$500 each in 2005) and because sampling them for sea lice was necessarily destructive. (Bluefin tunas such as T. maccoyii are large, fast-moving species that are obligate ram ventilators, and thus they respond very poorly to handling and immobilisation.) At the time of experimental sampling, tuna were caught and processed according to standard commercial harvesting techniques. Tuna were sampled using a smallscale purse-seine net within sea cages to isolate a portion of the school; each tuna was then captured individually by hand by divers on snorkel and transferred onto the harvest vessel. Tuna were then immediately pithed (spiked) through the head, bled from pectoral bleed cuts, cored using a 'Taniguchi tool', wired to destroy the upper spinal nerves, and the gills and viscera were then excised. Fish were tagged and 
lengths and weights were recorded later at the time of packaging onshore. Condition index was calculated using the South Australian tuna industry formula: estimated whole weight = (gilled and gutted weight/ $0.87) /$ length $^{3}$; mean whole weights, lengths and condition indices for each sample are presented in Table 2.

On board the harvest vessel, tuna were examined for parasites with the naked eye as soon as possible after each was caught and processed (usually within 3 min of death). Parasites were collected and fixed in 100\% ethanol. The true numbers of sea lice may well be higher than the numbers collected, as handling of the tuna during harvest may remove some lice. Copepods were identified later, after clearing in lactic acid, mounting on slides and examination under high-power microscopy while referring to taxonomic descriptions and illustrations in Ho \& Lin (2004) and Cressey \& Cressey (1980).

Sea lice infections on the skin of Thunnus maccoyii were characterised for each sea cage on each sampling date by prevalence (the no. of host infections as a proportion of the population at risk) and mean intensity (the avg. no. of parasites in each infected host) (Bush et al. 1997). On those dates when sea lice were detected, Kruskal-Wallace tests were used to determine whether mean numbers from the 4 sea cages differed significantly, and thus whether pooling of the data from the different cages was valid. As many zeros were present in some intensity data on some sample dates (resulting in bootstrap confidence intervals for mean intensities being 0), mean abundance (the avg. no. of parasites in all hosts, Bush et al. 1997) was also calculated for statistical comparison of sea lice counts on different sample dates. To determine whether there were any statistical differences in these infections among sea cages within a particular sample date, prevalence was compared using Fischer's Exact Test, and mean intensities (and mean abundances) were compared by bootstrap t-test with 2000 replications, in pairwise combinations of data from different sea cages, using the software 'Quantitative Parasitology 3.0' (Reiczigel \& Rózsa 2005). Where no significant differences were found among sea cages for prevalence ( $p>0.25$ in Fisher's Exact Test) and for mean abundances ( $p>0.042$, alpha level after Bonferroni adjustment for multiple comparisons, i.e. 0.25 divided by 6 ) for 6 pairwise combinations of 4 cages, data from the different cages were pooled for each sample date. The pooled data for each sample date were then similarly compared with other sample dates in a pairwise fashion using Fischer's Exact Test for prevalence and bootstrap $t$-test for mean abundances. Exact $95 \%$ confidence intervals were calculated for prevalence, and $95 \%$ bootstrap confidence intervals were calculated for mean intensities and abundances (Reiczigel \& Rózsa 2005).
Eye pathology among sampled tuna was characterised grossly according to the following 5-level scale of severity: 1 , mildly cloudy; 2, moderately cloudy; 3 , extremely cloudy; 4 , extremely cloudy with erosion of cornea; 5, eye perforated. Each tuna was thus assigned a score for both eyes with a total possible score of up to 10. To determine whether there was a relationship between sea lice intensity on individual fishes and eye pathology score, Spearman's rank correlation coefficients $\left(\mathrm{r}_{\mathrm{S}}\right)$ were calculated using the VassarStats online statistical calculator (http://faculty.vassar.edu/ lowry/VassarStats.html) for those sample dates in which sea lice were detected. Spearman's rank correlation coefficients were also calculated to determine whether there was any relationship between sea lice intensity and condition index for each sample date on which sea lice were detected; correlation coefficients were also calculated for the relationship between eye pathology and condition index. An alpha level of 0.05 was regarded as significant for statistical tests.

Mean daily water temperature data were extracted from the Southern Bluefin Tuna Telemetry-Based Environmental Monitoring Database of the South Australian Research and Development Institute.

\section{RESULTS}

Two species of caligid sea lice were detected: Caligus chiastos Lin et Ho, 2003 and a single individual identified as an undescribed species of Caligus on May 31, 2005. No attached chalimi larvae were detected; all individuals were adults. Because copepods were pooled at the time of collection and identified later, it is not known which individual tuna hosted the single specimen of Caligus sp.; data for all sea lice were therefore combined. The majority of sea lice were detected on the heads of tuna $(89.34 \%$, including $4.00 \%$ on the eyes), and the remainder were detected on the body. A single specimen of another dorsoventrally flattened copepod Euryphorus brachypterus was also detected on the skin of the dorsal body surface of a tuna sampled on August 22, but its occurrence on the skin is excluded from the data because this species is known to attach mainly to the pseudobranchs and gills of Thunnus maccoyii, and it is also readily distinguishable from caligid sea lice.

The overall prevalence for sea lice was relatively low, at one-fifth of all tuna sampled during the experiment $(20.0 \%)$. The grand mean intensity was 5.77 sea lice per infected tuna; the grand mean abundance was 1.15 sea lice per all tuna sampled. The maximum intensity of sea lice on any single tuna reached 42 individuals. On both sampling dates when sea lice were detected, the number of sea lice in the 4 cages did not 
differ significantly (Kruskal-Wallace statistic, K-W, in May = 2.3682, $\mathrm{p}=0.4996$; in July, $\mathrm{K}-\mathrm{W}=2.2743, \mathrm{p}=$ 0.5175). As these $\mathrm{p}$-values are greater than 0.25 , to increase the power of subsequent statistical tests, the data from each of the 4 sea cages were pooled on each date.

No sea lice were detected on the 10 fish sampled in early April at the time of transfer into cages (Fig. 1). After 6 wk in captivity, in late May, there was a significant increase in prevalence (peaking at 55.0\%); prevalence then declined again to levels not signifi-

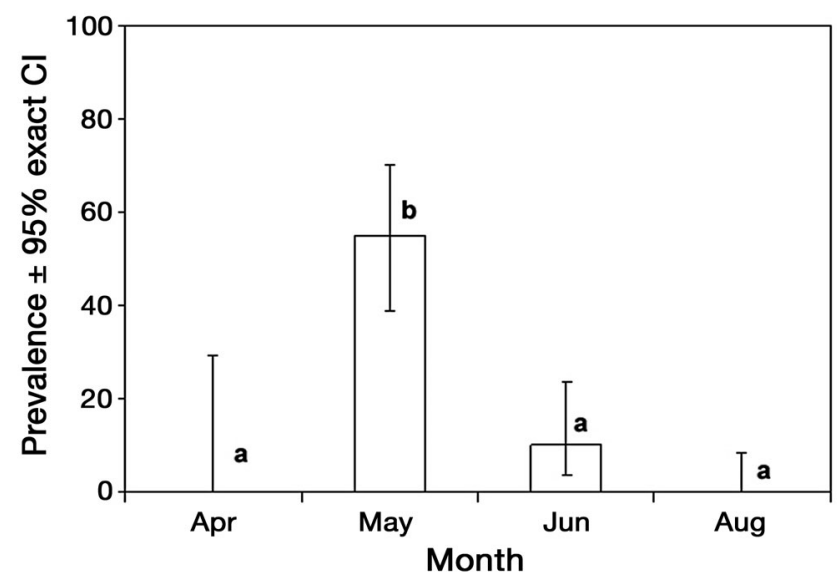

Fig. 1. Sea lice on Thunnus maccoyii. Prevalence and $95 \%$ exact condition index (CI) of Caligus chiastos (and a single specimen of an undescribed species of Caligus in May) on the skin of southern bluefin tuna off Port Lincoln, South Australia over a 4.5 mo farming period in 2005 (different cages within each month pooled). Different superscripts show month with prevalence that differs significantly in Fisher's Exact test $(p<0.05)$

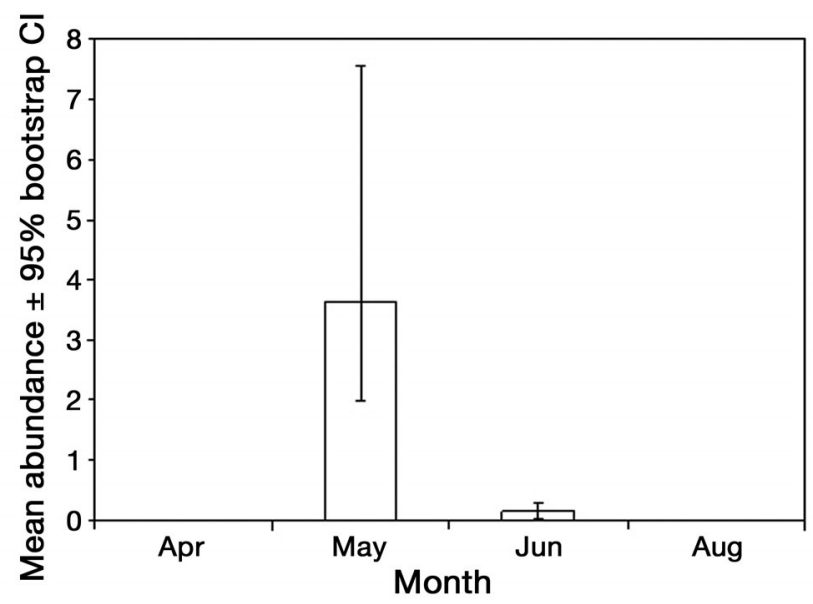

Fig. 2. Sea lice on Thunnus maccoyii. Mean abundances and bootstrap 95\% condition index (CI) of Caligus chiastos (and a single specimen of an undescribed species of Caligus in May) on the skin of southern bluefin tuna off Port Lincoln, South Australia over a 4.5 mo farming period in 2005 (different cages within each month pooled). Bootstrap $t$-tests within 2000 replications indicated that there were no significant differences between sample means ( $p>0.05)$ cantly different from the time of transfer into cages (10 and $0 \%$, respectively). Mean abundances of sea lice showed a similar trend (Fig. 2), with a peak in mean abundance 6 wk after transfer into cages (mean of 3.63 lice per tuna in the sample). Although this value of mean abundance in May did not significantly differ from mean abundances on the other 3 sampling dates, in this case the small samples sizes are likely to have resulted in a simple Type II error (that is, at $\alpha=0.05$, the null hypothesis that the mean abundances of sea lice did not differ significantly over time was falsely accepted).

Fig. 3 shows daily means of seawater temperature at $5 \mathrm{~m}$ depth near the cage sites over the sea lice monitoring period. The general trend was for a gradual decline in temperature, from ca. $20^{\circ} \mathrm{C}$ at the start of monitoring in early April to ca. $14^{\circ} \mathrm{C}$ at the end of August.

On the sampling date when both sea lice and eye pathology were first detected, in late May 2005, there was a strongly significant correlation between counts of sea lice and the severity of eye pathology $\left(\mathrm{r}_{\mathrm{S}, 38 \mathrm{df}}=0.654\right.$, $\mathrm{p}<0.001$ ); on this date $32.5 \%$ of Thunnus maccoyii were recorded to have grossly observable eye pathology, and the mean pathology score for affected tuna was 3.5 on the 10-point scale. On the next sampling date in early July, when sea lice prevalence had significantly declined, the correlation between sea lice intensity and the degree of eye damage was also highly significant $\left(\mathrm{r}_{\mathrm{S}, 38 \mathrm{df}}=0.568, \mathrm{p}<0.001\right) ; 7.5 \%$ of tuna were affected with eye pathology, and the mean score among these was 4.0. No sea lice were detected on the final sampling date in late August, although eye pathology was still evident, with $7.5 \%$ of tuna affected, and the mean score among these was 4.3. Fig. 4A shows a healthy eye of $T$. maccoyii, and Fig. 4B shows an eye sampled on August 22, 2005, which scored the maximum value of 5 on the scale of severity. Additionally, at the peak of the epizootic in late May, there was also a very strong inverse association between parasite inten-

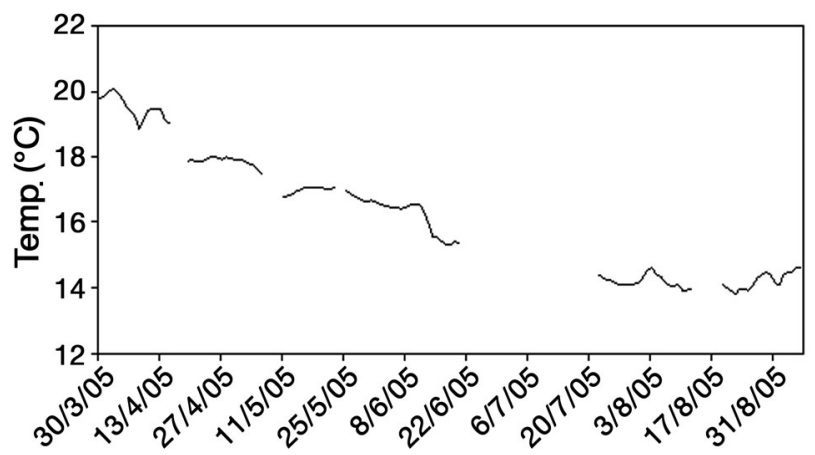

Fig. 3. Daily mean sea temperatures recorded by telemetry near experimental cages containing southern bluefin tuna Thunnus maccoyii during the period sea lice burdens were monitored in 2005. Dates are d/mo/yr 


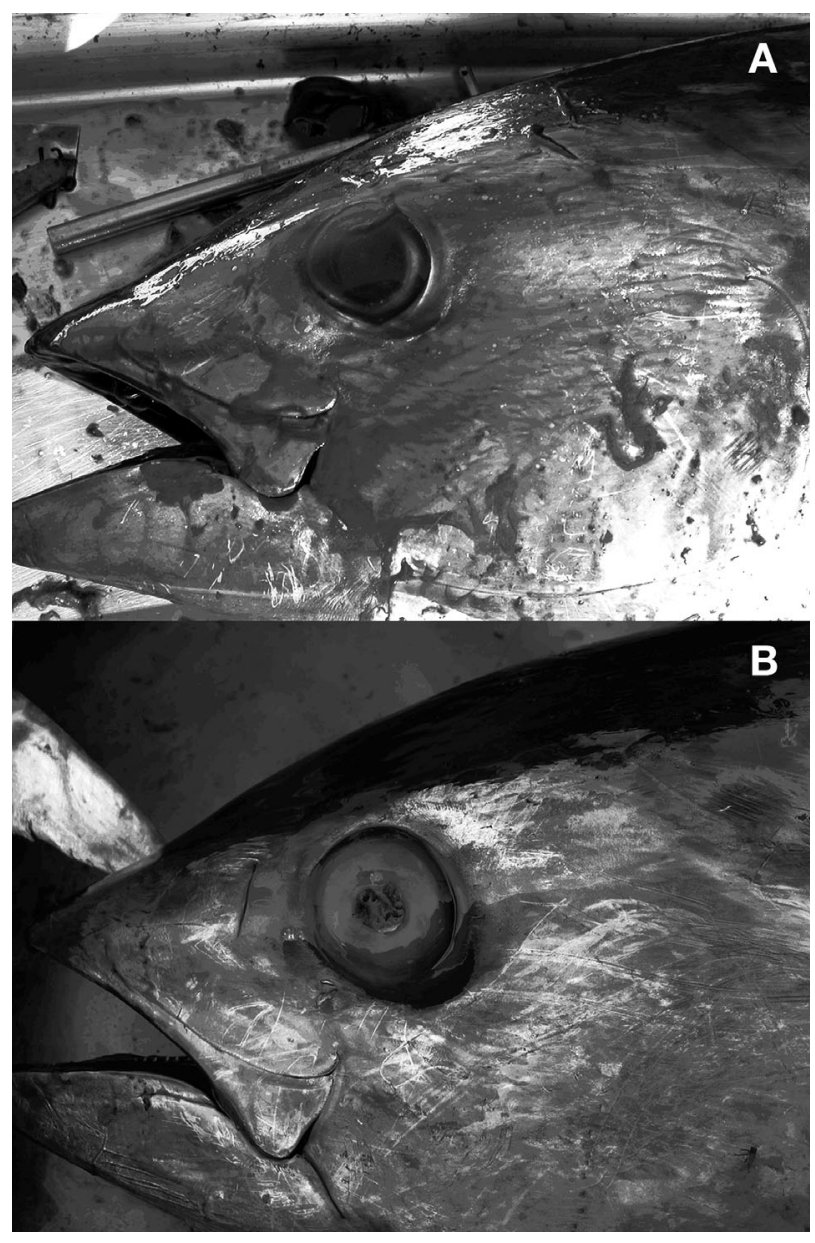

Fig. 4. Thunnus maccoyii. Eyes of southern bluefin tuna. (A) Normal eye. (B) Damaged eye from tuna, sampled on August 22, 2005. This eye scored the maximum value on the scale of severity of gross pathology, 5 (eye perforated, see 'Materials and methods')

sity and condition index $\left(\mathrm{r}_{\mathrm{S}, 38 \mathrm{df}}=-0.707, \mathrm{p}=0\right)$; in the only other sample in which sea lice were detected, in early July, there was no statistical association between lice intensity and condition index $\left(\mathrm{r}_{\mathrm{S}, 38 \mathrm{df}}=-0.195, \mathrm{p}=\right.$ 0.230 ). There was also a significant inverse relationship between eye pathology and condition index on the 2 samples dates when sea lice were detected (late May, $\mathrm{r}_{\mathrm{S}, 38 \mathrm{df}}=-0.513, \mathrm{p}=0.001$; early July, $\mathrm{r}_{\mathrm{S}, 38 \mathrm{df}}=-0.327, \mathrm{p}=$ $0.034) ;$ at the end of the season when no sea lice were detected, the correlation between eye pathology and condition index was no longer significant (late August, $\left.\mathrm{r}_{\mathrm{S}, 38 \mathrm{df}}=-0.167, \mathrm{p}=0.305\right)$.

\section{DISCUSSION}

The rapid and highly significant increase in prevalence of Caligus chiastos on the skin of southern bluefin tuna $6 \mathrm{wk}$ after transfer from the wild into cages, combined with the very strong, statistically significant relationship between sea lice counts and the severity of eye pathology (with a lower condition index) at this time, indicates that these parasites are associated with a significant loss of production in affected cages. Rough (2000) attributed the initial development of gross eye pathology directly to grazing on the cornea of tuna by sea lice. However, anecdotal observations indicate that the irritation caused by sea lice also leads infected Thunnus maccoyii to 'flash' (rub body surfaces against solid objects in the water), apparently in an attempt to remove these parasites from their heads and eyes. It is therefore possible that infected tuna injure their eyes when flashing; the likelihood of such injury probably increases when cage netting is fouled with bivalve species having sharpedged shells (such as blue mussels Mytilus galloprovincialis, hairy mussels Trichomya hirsuta and paper oysters Electroma georgiana). Opportunistic infections of the bacterium Aeromonas sp. have also been reported in association with louse-associated damage to tuna eyes (Munday et al. 2003). Whatever the primary cause of louse-associated eye pathology, once it progresses beyond mild cloudiness, affected tuna are likely to feed much less than those with unimpaired vision and thus rapidly lose condition. This conclusion is further supported by the significant correlation between eye pathology and condition index on the 2 sample dates when sea lice were detected in the present study.

Not all tuna appear to be susceptible to initial infections with sea lice, and even at the peak of the infection in May in the present study, $45 \%$ of the fish were not infected. The reasons for this are unknown, but Rough (2000) stated that stress during capture and towing to farm sites is a predisposing factor. While such stress does appear to trigger epizootics of sea lice on Thunnus maccoyii, this hypothesis requires verification. The treatment of farmed tunas with therapeutic chemicals to reduce lice burdens is considered impractical and uneconomical (Munday et al. 2003). If the stresses of capture and handling are later confirmed to be factors triggering epizootics of Caligus chiastos on farmed tuna, then the most effective means of reducing louseassociated losses in production would obviously be preventative measures, by minimising trauma to tuna during capturing and towing.

We also found that the peak in prevalence of Caligus chiastos on the skin of farmed Thunnus maccoyii at 6 wk after transfer into cages was followed by a significant decline in prevalence another 6 wk later. This decline may have been due simply to decreasing ambient water temperatures during the culture period (from ca. $17^{\circ} \mathrm{C}$ in late May, to ca. $14^{\circ} \mathrm{C}$ in late 
August 2005, Fig. 3), as such a drop would have undoubtedly reduced the growth and reproductive rate of these sea lice. For example, the generation times of C. elongatus and Lepeophtheirus salmonis are also longer at lower temperatures (Tully 1989). It has been hypothesised that infections of sea lice on salmonids are under the control of innate non-specific cellular defences. Cortisol implants in coho salmon Oncorhynchus kisutch suppressed the magnitude of inflammatory responses to L. salmonis and epithelial hyperplasia (Johnson \& Albright 1992), and cortisol implants in Atlantic salmon Salmo salar and Arctic charr Salvelinus alpinus also led to increased intensity of infection of $C$. elongatus (see Mustafa \& MacKinnon 1999). In the present study, however, it is unknown whether innate non-specific defences of tuna contributed to the decline in the epizootic of $C$. chiastos.

The epizootic of Caligus chiastos on Thunnus maccoyii in warm waters, and its decline as the water cooled during winter months, is generally consistent with epizootics described by Revie et al. (2002) for the closely related sea louse species $C$. elongatus on Atlantic salmon Salmo salar farmed off the west coast of Scotland. In the present study, we did not detect any chalimi larval stages of $C$. chiastos attached to the skin of farmed tuna, nor have we ever detected them on the external surfaces of other samples of tuna examined with a dissecting microscope (unpubl.). Additionally, we have not detected any stages of $C$. chiastos on wild tuna (unpubl.). This is in contrast with C. elongatus and Lepeophtheirus salmonis infecting farmed salmonids, as chalimi stages of these species do attach to the skin of these hosts (see Pike \& Wadsworth 1999). It seems likely, therefore, that $C$. chiastos cannot complete its life cycle on tuna, and that it is transmitted to tuna from other species of infected wild fishes that are attracted to tuna cages. Although there are no published studies documenting which fish species occur in and around tuna cages, such fish are known to include Degen's leatherjacket Thamnocanis degni, near the bottom of sea cages, and scad Trachurus sp., in upper waters, as well as other species, depending on the season (I. Svane, South Australian Research and Development Institute, pers. comm.). In addition, a range of elasmobranchs such as rays have also been observed in the vicinity of tuna cages. Moreover, such fishes in South Australian waters were considered by Kabata (1965) to be hosts of C. chiastos (or another species in this species group, as recorded under the name $C$. rapax); all 14 specimens identified from these elasmobranch hosts were male. Therefore, one or more of these wild teleosts or elasmobranchs around tuna cages may well act as hosts to the attached chalimi stages of $C$. chiastos. On the other hand, the hosts of chalimi may be benthic teleosts, as the chalimus larva of a closely related, unnamed species was detected attached to the fins of a wild flathead Platycephalus sp. in Hobart (C. J. Hayward et al. unpubl.).

The epizootic pattern of sea lice on the skin of farmed Thunnus maccoyii, followed by a decline in infection, differs from patterns of infection recorded among other species of metazoan ectoparasites on this host; yet it is generally similar to that of a digenean blood fluke infecting the heart of T. maccoyii. Hayward et al. (2007a) reported that there were no significant changes in the numbers of 2 species of ectoparasites (the copepod Euryphorus brachypterus and the polyopisthocotylean flatworm Hexostoma thynni) on the gills of farmed T. maccoyii over a 5 mo farming season in 2004; for a second species of copepod Pseudocycnus appendiculatus on the gills, there was a gradual increase over the season. In contrast, in the same season, Aiken et al. (2006) described an epizootic of the blood fluke Cardicola forsteri peaking 2 mo after tuna were transferred into cages and, as with sea lice in the present study, the infections declined after this time. The similarity in these patterns of epizootics are probably merely coincidental, as sea lice and blood flukes have few, if any, biological attributes in common.

The second species of sea louse Caligus sp. detected appears to be an undescribed species, which bears a general resemblance to C. macarovi Gusev, 1951. This latter species is known mostly from sauries Cololabis saira in the north Pacific Ocean off Japan and Mexico; it was also recorded once from the skin of a scombrid host Auxis sp. (see Cressey \& Cressey 1980 and references therein). Cressey \& Cressey (1980) note that it is not surprising that a caligid found on a pelagic prey species would occasionally be found on predatory scombrids. Similarly, in addition to the single individual of Caligus sp. we collected from Thunnus maccoyii in the present study, we detected several more individuals from a sample of blue mackerel Scomber australasicus that were netted inside a tuna cage, and these may well be the primary host of Caligus sp.

In the present study, we also detected a female individual of a dorsoventrally flattened copepod Euryphorus brachyterus, a species resembling caligids, which was attached to the skin of the body of one farmed tuna in late August. However, this species usually attaches to pseudobranchs and gills and is relatively common on both farmed and wild tuna (see Rough 2000, Hayward et al. 2007a). This copepod also appears to have been detected once previously on the skin of wild Thunnus maccoyii, attached near the anal and second dorsal fins (see images of 'Copepod type 5' in Rough 2000). In both cases, females attached to the skin did not bear egg sacs; these may have been lost as a result of exposure to increased drag when attached to this 
habitat (compared with a lesser amount on copepods exposed only to the ventilation current).

In conclusion, we found that a species of parasite not known from any species of wild tuna can be acquired under aquaculture conditions, apparently from other host fishes in the vicinity of sea cages and that the infestations of this parasite are very strongly associated with gross pathology of the eye and lost condition in the farmed tuna.

Acknowledgements. We thank the following: V. Lindsay, A. Watkins and DI Fishing Pty., Dr. J. Buchanan and the South Australian Research and Development Institute, Dr. P. Thomas and Flinders University, D. Warland of Sekol Pty., D. Ellis and the Tuna Boat Owners' Association and D. Foote. Mean daily temperature data was extracted from the output of Aquafin Cooperative Reserach Centre (CRC) project 2001/104, 'Aquafin CRC - Southern Bluefin Tuna Aquaculture Subprogram: tuna environment-development of regional environmental sustainability' (principal investigators J. Tanner and M. Loo, SARDI) and is used with permission from S. Clarke, SARDI. This work formed part of a project of Aquafin CRC and received funds from the Australian Government's CRCs Program, the Fisheries Research and Development Corporation and other CRC participants.

\section{LITERATURE CITED}

Aiken HM, Hayward CJ, Nowak BF (2006) An epizootic and its decline of a blood fluke Cardicola forsteri in farmed southern bluefin tuna Thunnus maccoyii. Aquaculture 254:40-45

Bush AO, Lafferty KD, Lotz JM, Shostak AW (1997) Parasitology meets ecology on its own terms: Margolis et al. revisited. J Parasitol 83:575-583

Cressey R, Cressey HB (1980) Parasitic copepods of mackereland tuna-like fishes (Scombridae) of the world. Smithsonian Institution Press, Washington, DC

Hayward CJ, Aiken HM, Nowak BF (2007a) Metazoan parasites on gills of southern bluefin tuna Thunnus maccoyii do not rapidly proliferate after transfer to sea cages. Aquaculture 262:10-16

Hayward CJ, Bott NJ, Itoh N, Iwashita M, Okihiro M, Nowak BF (2007b) Three species of parasites emerging on the gills of mulloway Argyrosomus japonicus (Temminck \&

Editorial responsibility: David Marcogliese,

Montréal, Quebec, Canada
Schlegel, 1843), cultured in Australia. Aquaculture 265:27-40

Ho JS, Lin CL (2004) Sea lice of Taiwan (Copepoda: Siphonostomatoida: Caligidae). Sueichan Press, Keelung

Johnson SC, Albright LJ (1992) Effects of cortisol implants on the susceptibility and the histopathology of the responses of naïve coho salmon Oncorhynchus kisutch to experimental infection with Lepeophtheirus salmonis (Copepoda: Caligidae). Dis Aquat Org 14:195-205

Kabata Z (1965) Copepods parasitic on Australian fishes. IV. Genus Caligus (Caligidae). Ann Mag Nat Hist 13:109-126

Lester RJG, Hayward CJ (2006) Phylum Arthropoda. In: Woo PTK (ed) Fish diseases and disorders, Vol 1. Protozoan and metazoan infections, 2nd edn. CABI Publishing, Oxford, p 463-562

Munday BL, Sawada Y, Cribb T, Hayward CJ (2003) Diseases of tunas, Thunnus spp. J Fish Dis 26:187-206

Mustafa A, MacKinnon BM (1999) Atlantic salmon, Salmo salar L., and Arctic charr, Salvelinus alpinus (L.): comparative correlation between iodine-iodide supplementation, thyroid hormone levels, plasma cortisol levels and infection intensity with the sea louse Caligus elongatus. Can J Zool 77:1092-1101

Nowak BF (2004) Assessment of health risks to southern bluefin tuna under current culture conditions. Bull Eur Assoc Fish Pathol 24:45-51

Øines Ø, Heuch PA (2005) Identification of sea louse species of the genus Caligus using mtDNA. J Mar Biol Assoc UK 85:73-79

Parker RR (1969) Validity of the binomen Caligus elongatus for a common parasitic copepod formerly misidentified with Caligus rapax. J Fish Res Board Can 26:1013-1035

Pike AW, Wadsworth SL (1999) Sea lice on salmonids: their biology and control. Adv Parasitol 44:233-337

Reiczigel J, Rózsa L (2005) Quantitative parasitology 3.0. Distributed by authors, Budapest. Available at: www.behav.org/qp/qp.htm

Revie CW, Gettinby G, Treasurer JW, Rae GH (2002) The epidemiology of the sea lice Caligus elongatus Nordmann in marine aquaculture in Atlantic salmon Salmo salar L. in Scotland. J Fish Dis 25:391-399

Rough KM (2000) An illustrated guide to the parasites of southern bluefin tuna Thunnus maccoyii. South Australian Research and Development Institute, Adelaide

Tully O (1989) The succession of generations and growth of the caligid copepods Caligus elongatus and Lepeophtheirus salmonis parasitising farmed Atlantic salmon smolts Salmo salar L. J Mar Biol Assoc UK 69:279-287

Submitted: June 15, 2007; Accepted: December 19, 2007

Proofs received from author(s): February 15, 2008 